\title{
Políticas Feministas da Vida, palavras finais
}

SUZANE DE ALENCAR VIEIRA E FABLANA MAIZZA

Nossas palavras finais se colocam de forma inversa e visam apresentar os artigos que compuseram os dois tomos do dossiê Ecologia e Feminismo: criaçôes políticas de mulheres indígenas, quilombolas e camponesas.

A proposta desse dossiê surgiu da inquietação de duas antropólogas que, vindas de pesquisas de campo entre populações indígenas e quilombolas, se encontram na ANPOCS e tentam tornar inteligível o que aprenderam com as mulheres indígenas e quilombolas e como nossas interlocutoras desorientaram nosso feminismo. Nos encontros ao longo das duas edições do Simpósio de Pesquisas Pós-graduadas da ANPOCS, juntaram-se a nós antropólogas, historiadoras e sociólogas no esforço de aproximar diferentes linhas do feminismo e os debates ecológicos contemporâneos, em que o "e" indica variação contínua e fecundante.

Queríamos antes de mais nada, agradecer às pesquisadoras que colaboraram conosco nesse projeto de discutir, aproximar e problematizar as conexões entre ecologia e feminismo. Tratou-se de um dossiê experimental, no sentido de que a proposta era fazer com que as autoras experimentassem preocupações nas quais feminismo e ecologia se conectavam, mas especialmente ouvir como nossas interlocutoras articulavam esses temas. Queríamos colocar nossas categorias sob a reformulação de nossas interlocutoras no intuito de perceber como suas relações e formulações acerca de domínios da experiência que tendemos a localizar como "natureza", "sociedade", entre outros, descentram tanto o pensamento feminista como o antropológico, formulando novas questões e apontando para entendimentos que nos ajudem a desconstruir algumas de nossas categorias analíticas.

Um aspecto estruturante da relação entre natureza e cultura no pensamento ocidental é a tendência de pensar esse par através de uma relação de dominação e controle. Entre as várias acepções dessa relação, seja pela via do pensamento ecológico, seja pela via do feminismo social-marxista na antropologia, Marilyn Strathern (1980) observa que os termos são assimilados em uma relação de hierarquia ou incorporação em que um dos termos domina ou controla o outro. Foi justamente no debate acerca da dicotomia natureza/cultura - e a hierarquização do social sob o natural - que o pensamento antropoló- 
gico passou recentemente por uma reviravolta na qual os limites entre humanos e não-humanos, orgânico e inorgânico, indivíduo e sociedade foram questionados. As metafisicas não-ocidentais (indígenas, quilombolas, camponesas, por exemplo) estão sendo levadas para o centro do debate, e através delas se aponta uma reconceitualização radical do social. O ímpeto de formatar as relações ecológicas dos coletivos indígenas, quilombolas e camponeses à perspectiva antropocêntrica está cada vez mais sob suspeita.

O conceito "natureza" também sempre esteve no foco das discussões feministas, seja para denunciar uma suposta proximidade das mulheres com o mundo natural que justificaria a submissão universal da mulher, como sugerido pelo feminismo social-marxista (Ortner 1974; Rosaldo 1974, entre outros/ as), seja para refutar qualquer concepção que aproxime corpos biológicos ao 'dado' e 'natural', conforme colocado pelo pós-feminismo e nas teorias Queer (Preciado 2015, Butler 1999, entre outros/as). Os movimentos anticoloniais e anticapitalistas, por sua vez, apropriam-se desta sugerida - ou refutada proximidade das mulheres com a "natureza” e a invertem, criando assim identidades políticas através de termos normalmente atribuídos às mulheres como cuidado, maternidade, entre outros, e da "defesa do meio ambiente".

Assim, tanto na antropologia como no movimento feminista contemporâneo há uma tentativa de questionar e reformular dicotomias analíticas que estruturam o pensamento Ocidental. O que vemos na teoria antropológica contemporânea é o esforço de fazer com que conceitos como 'mulher', 'corpo', 'sexo', 'gênero, 'humano,' 'animal', ao serem estudados em diferentes coletivos humanos, coloquem problemas que afetem esses mesmos conceitos tal como eles são concebidos por nós. De uma forma similar, o pós-feminismo e o ecofeminismo tensionam nosso entendimento do natural: o pós-feminismo por recusá-lo completamente, argumentando que o natural é, de fato, um conceito político, e o ecofeminismo contemporâneo por se apropriar do termo e usá-lo de forma reversa, criando novos significados. Os artigos que apresentaremos aqui, dialogam, de forma direta ou indireta, com essas preocupações.

Nelly Duarte nos mostra, no tomo anterior, que, entre os Marubo, o conhecimento das mulheres passa pelo fazer, que seria melhor traduzido pelos termos 'criar' e 'fazer existir'. As mulheres são particularmente conhecidas por aquilo que é "transformado pelas pontas de suas mãos" (nokê mevi revõsho shovima awe). O "fazer" é um conhecimento que a mão faz existir, um conhecimento que se move sempre de fora para dentro e vice-versa, e que faz crescer a pessoa. Para as mulheres Marubo, o que se transforma nas pontas de suas mãos são cestas, abanadores, peneiras, saias e pintura corporal (kene). Nelly Duarte explica que estes objetos e desenhos são sempre produzidos para fins utilitários, mas também no intuito de se conseguir realizar o desenho e conhecer a história dos objetos. Para as mulheres, os bens que manufaturam são a base sobre a qual se eleva a sua autoestima, como prova de seu valor e de seu conhecimento: aquela que não tem o saber nas mãos, também não tem o saber na alma. Esse saber está vinculado ao pertencimento clânico herdado por cada mulher, que marca as diferenças entre os estilos e caminhos da transmissão. Nelly irá nos guiar para um mundo onde as mulheres estão sempre fazendo algo bonito com suas mãos, além de serem grandes conhecedoras do sistema clânico, enfim, a autora irá nos mostrar um saber feminino indígena pouco descrito por antropólogos/as.

Carolina Rocha Silva resgata a história de duas escravas mestiças, Joana e Custódia de Abreu, que no Piauí colonial foram acusadas de participar de encontros noturnos firmados por pactos diabó- 
licos. Através de uma análise histórica da segunda metade do século XVIII pelas fontes inquisitoriais, a autora busca elucidar o lugar das mulheres pobres, negras, indígenas e mestiças no Brasil colonial. $\mathrm{O}$ que descobrimos é o grande uso de práticas mágicas, a intolerância e demonização das práticas religiosas de origem africanas e indígenas, além da misoginia que desacreditou as falas e feitos das mulheres. Suas descrições ecoam preocupantemente com o Brasil contemporâneo. Se o tema da caça às bruxas na Europa vem sendo explorado de forma instigante por historiadores e também por pesquisadoras feministas (como por exemplo, Silvia Federici), mostrando como se criou uma segunda classe de pessoas no pensamento moderno; Carol Rocha, de forma não menos brilhante, irá argumentar que a mesma caça às bruxas ocorreu no Brasil colonial, mas se dirigindo especificamente às mulheres não-brancas - e apontando assim para a grande questão racial que emerge nesse país desde sua invasão pelos portugueses.

Renata Pacheco trará um artigo etnográfico que discute, de forma inédita, a situação das pescadoras e cultivadoras de ostra da Ponta Oeste da Ilha do Mel - Paraná. A autora falará sobre a invisibilidade dessas mulheres com relação ao mundo de fora da ilha, e também com relação ao Estado, apesar delas serem responsáveis pela permanência da comunidade em seu local de origem, mesmo depois da demarcação de uma área de proteção ambiental. A autora nos atenta assim ao ativismo político e ecológico dessas mulheres frente às pressões e impactos do Estado. Passamos a conhecer essas pescadoras através de conversas cotidianas, preocupações corriqueiras, suas idas e vindas para pescar e cuidar de ostras; e o que vemos é a liderança feminina que visa não apenas proteger a vida humana na ilha, mas também todos seus habitantes não-humanos, no mar e na terra. É através de sua pessoa em campo e de conversas informais, que Renata irá nos descrever o universo de suas interlocutoras, pouco conhecido para pessoas de fora da ilha.

Stéphanie Tselouiko fará uma reflexão sobre os projetos socioambientais e as mulheres indígenas: até que ponto projetos de cunho ecológicos, mais especificamente ecofeministas, dialogam com a realidade das mulheres Mẽbêngôkre-Xikrin? - pergunta-se a autora. Através da descrição etnográfica da participação das mulheres em um projeto, pensando por elas mesmas, de criação de uma roça coletiva, a autora irá percorrer sobre a experiência das mulheres Mebengôkre no mundo dos projetos. Em um primeiro momento, as mulheres buscaram o projeto de "roça das mulheres" (menire nhõ puru) como fonte de renda para acessarem alguns bens materiais da cidade. Mas com o decorrer do tempo, há uma inversão da lógica inicial, e ao invés de produzirem mandioca para vender, as mulheres optam por ampliar a produção das roças de família de cada uma. Ou seja, o mercado as interessa menos do que o bem-estar e abundância de alimentos para suas famílias. Tselouiko irá argumentar que essa escolha está também conectada com o fato de que as roças fornecem não apenas alimentos, mas também a força criativa dos laços afetivos interpessoais que condicionam a perenidade do grupo. Para os/as Mẽbêngôkre-Xikrin, o saber-fazer hortícola é uma forma de criação que confere a verdadeira condição humana.

A etnografia é também o caminho escolhido por Luiza Flores para deslocar a universalidade da categoria de gênero e a acepção identitária do gênero e da ação política feminista. Feminismo como força de cura e de cuidado não é um retorno ao essencialismo que vincula a categoria mulher à natureza apartando as mulheres da política. Passamos dos símbolos e atributos de gênero para o terreno de forças 
e afetos. Os dados de campo perfazem outros movimentos de deslocamento em relação às noções de guerra, de ação política/resistência, natureza a partir de outra linguagem conceitual.

A vida é retomada na discussão que Flávia Paniz provoca em torno das categorias de gênero e de etnicidade tal como são ativadas politicamente pelas mulheres curdas. O artigo "Diálogos entre o Antropoceno e o feminismo pós-colonial: notas sobre ecologia, gênero e etnicidade na luta por autonomia das comunidades curdas no Norte da Síria”, aqui apresentado, descreve as mobilizações das mulheres curdas na luta pela autonomia de quatro territórios curdos e da recente reconfiguração ecológica das pautas políticas curdas. As mulheres assumem a tarefa de reorganização da vida nas comunidades curdas a partir do lema mulher, vida e liberdade (Jîn, Jîan e Azadî). Se a degradação ambiental é uma das formas de controlar e subjugar as minorias étnicas, a luta pelo território se torna uma luta ecológica pela produção e reprodução da vida no lugar.

A partir das obras da artista inga Rosa Tisoy, Tatiana Lotierzo reflete sobre concepções de conhecimento e de criação. No artigo "Dos corpos, a terra: notas sobre a criatividade no trabalho de Rosa Tisoy", a autora articula a arte e a vida a partir da política ética e estética do bem-viver indígena. Bem-viver (suma kaugsay) que é aqui vinculado ao conhecer, criar e partilhar, e depende de um "bonito pensar" (suma yuyay). As obras de Rosa Tisoy podem ser entendidas, segundo Lotierzo, como lugares onde o conhecimento se realiza como efeito da co-presença de seres que ali se encontram.

Ecologia e feminismo remete a interações teóricas, frutos de encontros de algumas práticas e teorias feministas com o debate ecológico atual. As preocupações feministas se entrecruzaram com o tema da vida e com formas de resistência que Miriam Tola (2016) identifica às políticas feministas da terra.

Caminhando ao lado de mulheres indígenas ou quilombolas por florestas e mulungus, talvez não nos demos conta do quão transformativo pode ser esse deslocamento/experiência a que nos expomos. Esses vários encontros teóricos e experiências nos levam a incorporar uma outra sensibilidade ecológica. Aprendemos a olhar para a terra e, tentando decifrar suas marcas, seus rastros e sinais, aprendemos sobre a vida das plantas e a criação. Muito mais do que uma paisagem ou um cenário para as relações sociais, a terra e outras formas de exterioridade despontam como um campo de produção da vida. No corpo dos textos que se unem neste Dossiê insurgem uma multiplicidade de outros que, em suas formas de relacionalidade e práticas ecológicas divergentes, protagonizam a contestação de noções hegemônicas de progresso e de crescimento.

Fabiana Maizza é doutora em Antropologia pela Universidade de São Paulo. Foi professora substituta do Departamento de Antropologia da UFPR em 2018 $e$ é, atualmente, professora da Universidade Federal do Pernambuco (UFPE).

Suzane de Alencar Vieira é doutora em Antropologia pelo Museu Nacionall UFRJ e professora da Universidade Federal de Góias. 


\section{REFERÊNCIAS BIBLIOGRÁFICAS}

BUTLER, Judith. 1999. Gender Trouble: feminism and the subversion of identity. New York: Routledge. ORTNER, Sherry. 1974. "Is Female to Male as Nature is to Culture?”. In: ROSALDO, Michelle. \& LAMPHERE, Louise. (eds.). Women, Culture and Society. Stanford: Stanford University Press, pp. 67-87.

PRECIADO, Paul Beatriz. 2015. Manifesto contrassexual: práticas subversivas de identidade. São Paulo: N-1 Edições.

ROSALDO, Michelle. 1974. "Women, culture and society: a theoretical overview”. In: ROSALDO, Michelle. \& LAMPHERE, Louise. (eds.). Women, Culture and Society. Stanford: Stanford University Press, pp.17-43.

STRATHERN, Marilyn. 2014. "Sem natureza, sem cultura: o caso Hagen”. In: O efeito etnográfico e outros ensaios. São Paulo: Cosac Naify.

TOLA, Miriam. 2016. "Composing with Gaia: Isabelle Stengers and the Feminist Politics of the Earth". PhoenEx 11 (1):1-21.

RECEBIDO: $15 / 04 / 2019$

APROVADO: $25 / 04 / 2019$ 